\title{
Covid-19: weathering the storm
}

\author{
Fiona Godlee editor in chief
}

The BMJ

The UK is at last in near lockdown. While further measures may be needed, the government's announcement on Monday 23 March has brought the country nearly into step with its European neighbours. If we are indeed only two weeks behind Italy, the peak of the covid-19 pandemic is on its way. There is an eerie calm, as when the sea recedes before the tsunami. Few of us can imagine what lies ahead.

For some, especially in London, the wave has already hit. Intensive care units are full, and hard decisions are becoming harder. On BMJ Opinion Daniel Sokol hopes that hospitals will establish "ethical support units" to help clinicians choose which patients to prioritise (https://bit.ly/2WIITsI). In our rapid responses David Barer makes a stark call for people aged over 60 to prepare for a lack of ventilatory support and to express their preferences for palliative care until WHO declares an end to the pandemic (bit.ly/3bqvubU).

Every aspect of the NHS is being reorganised to meet the increased demand, say John Willan and colleagues (doi:10.1136/ bmj.m1117), but $20 \%$ of its workforce is either ill or in self isolation. Healthcare workers are at higher risk of infection, and personal protective equipment is still lacking, despite government assurances. The waiting and workload are worsened by fear and fatigue. Staff, already stretched, are now scared.

Could some of this have been avoided? Many think so. Over the years, opportunities to research influenza-like illness have been missed and money squandered on ineffective antiviral drugs (doi:10.1136/bmj.m626). The NHS has been stripped of resilience by years of attrition compounded by lack of investment in social care. Public health services have been systematically decimated and dismantled. The UK's idiosyncratic response to the pandemic has been guided by questionable modelling rather than by long established fundamentals of communicable disease control (https://bit.ly/ 2UzRZnI).

David Oliver counsels against political point scoring: there will be time enough for that when this is over, he says (doi:10.1136/ bmj.m1153). So we should for the moment focus on things that will help us weather the impending storm. An urgent return to community contact tracing, says Allyson Pollock (bit.ly/ 2ULmgAj). Testing of frontline healthcare workers, says Julian Peto (bit.ly/2QJLjCx). Lowering the baseline of underlying illness, say Robert Hughes and colleagues (bit.ly/33PhNRa). To these, like Mary Black (bit.ly/2JcjiiF), I would add three more necessary things: candour about the scientific and political uncertainties, kindness to ourselves and each other, and courage.

For our latest content on the covid-19 pandemic go to bmj.com/coronavirus.

Published by the BMJ Publishing Group Limited. For permission to use (where not already granted under a licence) please go to http://group.bmj.com/group/rights-licensing/ permissions 